\title{
Survey of Fusarium species associated with crown rot of wheat and barley in eastern Australia
}

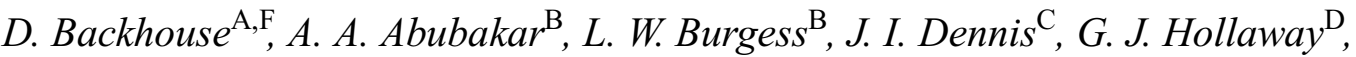 \\ G. B. Wildermuth ${ }^{\mathrm{E}}$, H. Wallwork ${ }^{\mathrm{C}}$ and F. J. Henry ${ }^{\mathrm{D}}$ \\ ${ }^{\text {A }}$ School of Environmental Sciences and Natural Resources Management, University of New England, Armidale, \\ NSW 2351, Australia.

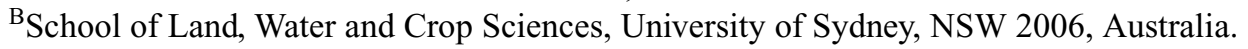 \\ ${ }^{C}$ South Australian Research and Development Institute, GPO Box 397, Adelaide, SA 5001, Australia. \\ Department of Primary Industries, Primary Industries Research Victoria, Private Bag 260, Horsham, Vic. 3401, \\ Australia. \\ ${ }^{E}$ Leslie Research Centre, Department of Primary Industries, PO Box 2282, Toowoomba, Qld 4350, Australia. \\ ${ }^{\mathrm{F}}$ Corresponding author; email: dbackhou@pobox.une.edu.au
}

\begin{abstract}
Fusarium species associated with crown rot were isolated and identified from 409 wheat, barley or durum wheat crops from the eastern Australian grain belt between 1996 and 1999. Fusarium pseudograminearum was almost the only species isolated from crops in Queensland and New South Wales. F. pseudograminearum was also the most common species in Victoria and South Australia, but F. culmorum was frequently isolated in these states. F. culmorum accounted for more than $70 \%$ of isolates from the Victorian high-rainfall $(>500 \mathrm{~mm})$ region and the South-East region of South Australia. F. culmorum comprised $18 \%$ of isolates from the Victorian medium-rainfall $(350-500 \mathrm{~mm})$ region, and 7\% of isolates from each of the Victorian low-rainfall region and the Mid-North region of South Australia. F. avenaceum, F. crookwellense and F. graminearum were isolated very infrequently. The proportion of F. culmorum among isolates of Fusarium from districts in Victoria and South Australia was strongly correlated with climatic conditions around the end of the growing season, especially with rainfall in November.
\end{abstract}

\section{Introduction}

Crown and foot rots caused by species of Fusarium are among the most widespread and damaging of soil- and residue-borne diseases of wheat and barley. Prior to the 1960s, Fusarium culmorum was considered to be the most important species responsible for these diseases in Australia (Geach 1932; Millikan 1942; Butler 1961). Much of this early work was done in Victoria, and treated F. culmorum as part of a complex of fungi responsible for 'common root rot'.

Crown rot caused by $F$. pseudograminearum was first detected in Queensland in 1951 and northern New South Wales in 1955 (Magee 1957). This fungus was originally reported as $F$. graminearum Group 1 or its perfect state Gibberella zeae, but was described as a separate species by Aoki and O'Donnell (1999). Crown rot caused by F. pseudograminearum is now recognised as a major disease in Queensland and northern New South Wales (Murray and Brown 1987; Klein et al. 1990).
F. pseudograminearum was first found in Victoria in 1965 (Price 1970). Subsequently, Chambers (1972) surveyed root infections in cereal crops throughout Victoria and found that F. culmorum was prevalent only in the southern, high-rainfall districts. He suggested that either the prevalence of F. culmorum had changed, or that earlier workers (Geach 1932) had failed to identify the fungus properly. On the basis of restricted distribution of $F$. culmorum and infrequent isolation of $F$. pseudograminearum, Chambers (1972) regarded Fusarium root diseases of being of less importance in Victoria than previously believed.

Burgess et al. (1975) surveyed wheat crops with crown rot in western Victoria, New South Wales and southern Queensland. They found that F. pseudograminearum was the predominant fungus associated with crown rot in all regions, and that F. culmorum and other potentially pathogenic species such as $F$. avenaceum were uncommon. However, they did not survey most of the Wimmera or the high-rainfall 


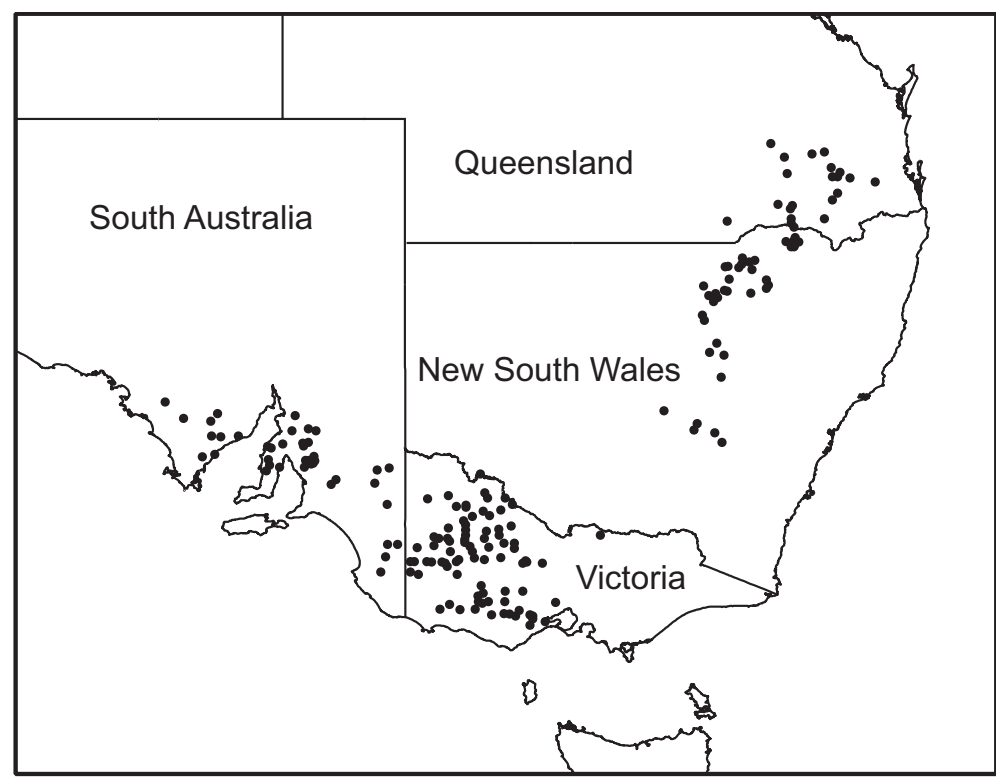

Fig. 1. Location of crops sampled for Fusarium species (๑) in eastern Australia.

districts of Victoria, where early records of F. culmorum were most frequent (Geach 1932; Millikan 1942; Chambers 1972). Analysis of historical records and culture collection accessions suggested that $F$. culmorum was widespread in these districts and in adjacent areas of South Australia (Backhouse and Burgess 2002), although these data could not be used to determine the prevalence of $F$. culmorum relative to $F$. pseudograminearum.

For the past three decades, crown rot caused by F. pseudograminearum has been regarded as the disease of greatest relative importance in the northern grain growing areas of New South Wales and Queensland (Murray and Brown 1987). In recent years, crown rot has increased in significance in Victoria and South Australia due to greater adoption of the practice of retaining cereal residues and increased areas sown to highly susceptible durum wheat cultivars. Although F. pseudograminearum has frequently been isolated from infected plants, there have been indications that other species of Fusarium may also be involved (Fedel-Moen and Harris 1987; E. Capio and H. Wallwork, unpublished). This suggests that crown rot in southern Australia may have a complex aetiology similar to that in North America (Smiley and Patterson 1996). Management of the disease in Victoria and South Australia depends on identifying the predominant causal fungi, because of potential differences in epidemiology and in resistance to the various pathogenic species of Fusarium.

Confusion over the importance of F. culmorum, the lack of any comprehensive survey in southern areas of Fusarium species from crown tissue rather than from roots, and the possibility that other species of Fusarium may also be of importance as pathogens led to the establishment of disease surveys between 1996 and 1999. The aim was to determine the most common species of Fusarium associated with crown rot symptoms on cereals, with particular emphasis on Victoria and South Australia. Surveys were also done in New South Wales and Queensland for comparative purposes.

\section{Methods}

The intention of the survey was to identify Fusarium species associated with crown rot, so sampling was targeted at crops with symptoms of the disease in areas where crown rot was considered most likely to occur. Plants close to harvest maturity were collected from 1996 to 1999 from wheat (Triticum aestivum), barley (Hordeum distichon and $H$. vulgare) or durum wheat (T. turgidum var. durum) crops. Plants with symptoms of stem browning were collected from 60 crops in Queensland, 85 crops in New South Wales, 133 crops in Victoria and 113 crops in South Australia (Fig. 1). Plants were collected from a further 62 crops in the higher-rainfall areas of Victoria during 1998 and 1999, irrespective of the presence of symptoms. From each field, the leading tillers of 25 plants were dissected out and sent to the Fusarium Research Laboratory at the University of Sydney. Each stem base was washed thoroughly under running water and surface sterilised with $1 \% \mathrm{w} / \mathrm{v}$ sodium hypochlorite in $10 \% \mathrm{v} / \mathrm{v}$ ethanol for $2 \mathrm{~min}$.

In the 1996 season (samples from Queensland only), the 25 stem bases from each crop were divided into the subcrown internode, the region immediately around the crown, the first node above the crown, and $2-\mathrm{cm}$ lengths of each of one crown root and one seminal root. The five tissue pieces from each stem were plated onto half-strength potato-dextrose agar supplemented with $0.013 \mathrm{~g} / \mathrm{L}$ dichloronitroaniline, $0.16 \mathrm{~g} / \mathrm{L}$ streptomycin sulphate and $0.06 \mathrm{~g} / \mathrm{L}$ neomycin sulphate. Cultures were incubated under a combination of white and near-ultraviolet fluorescent lights with a $12 \mathrm{~h}$ photoperiod and $22 / 25^{\circ} \mathrm{C}$ night/day temperature cycle. All cultures resembling Fusarium species were subcultured onto carnation-leaf agar (CLA), incubated under the same conditions, and identified to species. It was found that all species known to be pathogenic to cereals formed red-pigmented colonies on the isolation plates, and that including root tissue did not increase the efficiency of isolation, so in subsequent years only the subcrown internode and the basal $2 \mathrm{~cm}$ of the stem above this were separated out and plated, and only red-pigmented colonies were identified to species. 


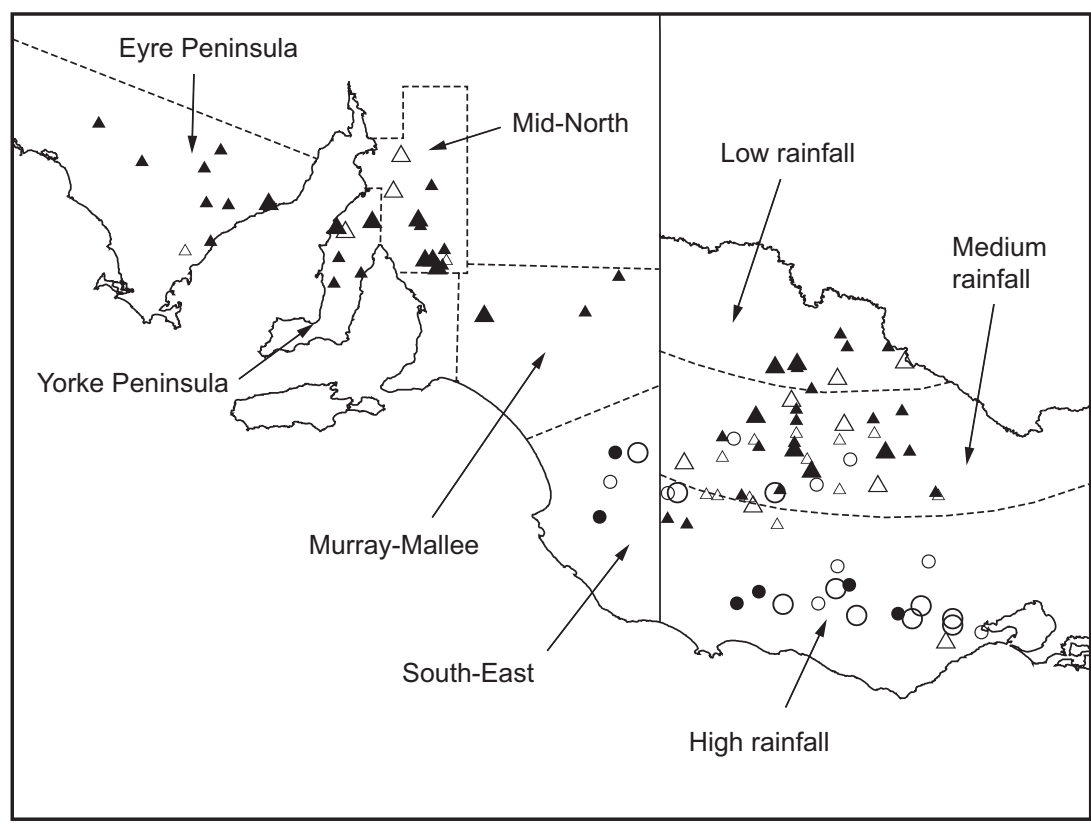

Fig. 2. Relative prevalence of Fusarium pseudograminearum and F. culmorum at sampling sites in Victoria and South Australia. Only sites from which a minimum of 15 cultures of either species were isolated from 25 plants are included. $\Delta$ F. pseudograminearum only; $\triangle$ predominantly F. pseudograminearum; $\bigcirc$ predominantly F. culmorum; - F. culmorum only. Small symbols represent individual crops; large symbols represent pooled data from two or more crops at one locality.

Table 1. Number of crops surveyed in each region from 1996 to 1999 in which Fusarium species were found associated with crown rot symptoms, and total number of plants infected with $F$. pseudograminearum or $F$. culmorum in each region

\begin{tabular}{|c|c|c|c|c|c|c|}
\hline \multirow[t]{2}{*}{ Region } & \multicolumn{4}{|c|}{ Crops surveyed with Fusarium present } & \multicolumn{2}{|c|}{ Number of plants infected with } \\
\hline & 1996 & 1997 & 1998 & 1999 & F. pseudograminearum & F. culmorum \\
\hline Queensland & 23 & 26 & 3 & 5 & 1104 & 3 \\
\hline New South Wales & - & 3 & 39 & 33 & 1052 & 0 \\
\hline Vic high rainfall & - & 7 & 20 & 66 & 387 & 856 \\
\hline Vic medium rainfall & - & 8 & 33 & 15 & 869 & 196 \\
\hline Vic low rainfall & - & 6 & 13 & 13 & 546 & 44 \\
\hline SA South-East & - & 1 & 1 & 5 & 33 & 112 \\
\hline SA Murray Mallee & - & 1 & 3 & 5 & 102 & 1 \\
\hline SA Mid-North & - & 27 & 19 & 5 & 672 & 52 \\
\hline SA Yorke Peninsula & - & 4 & 6 & 5 & 273 & 2 \\
\hline SA Eyre Peninsula & - & 3 & 6 & 5 & 268 & 2 \\
\hline
\end{tabular}

Identification was based on macroconidial morphology and perithecial production on CLA, according to the criteria of Burgess et al. (1994).

For samples from Queensland and New South Wales, the numbers of plants infected with known pathogenic species of Fusarium were summed over all years and all crops within each state. Because sites and areas surveyed were not necessarily comparable between years, no attempt was made to do comparisons on a seasonal basis. Victoria and South Australia were divided into regions (Fig. 2) to give a more detailed breakdown of results. Victoria was divided into regions of low $(<350 \mathrm{~mm})$, medium $(350-500 \mathrm{~mm})$ and high $(>500 \mathrm{~mm})$ rainfall. South Australia was divided into five geographical regions: South-East (predominantly $>500 \mathrm{~mm}$ rainfall); Murray Mallee $(<350 \mathrm{~mm}$ ); Mid-North (350-500 mm); Yorke Peninsula (350-500 mm); and Eyre Peninsula (predominantly $<400 \mathrm{~mm}$ rainfall).

The relationship between climate and prevalence of F. culmorum in Victoria and South Australia was explored because this species appeared to be more common in high-rainfall areas. The most recent available long-term climate averages for 26 meteorological stations representative of the wheat-growing areas of Victoria and South Australia were obtained from the Bureau of Meteorology. Isolation data were pooled from crops in the surrounding districts. Only crops from which at least 15 isolates of $F$. culmorum or F. pseudograminearum had been obtained from 25 plants were included. Correlations between the proportion of isolates of $F$. culmorum among the total of either F. culmorum or F. pseudograminearum for each district, and the long-term averages of minimum, maximum and mean temperatures and rainfall for each month, and annual minimum, maximum and mean temperature and rainfall were calculated. The correlation between proportion of F. culmorum and growing degree-days during the wheat season (Smiley and Patterson 1996) was also calculated. Long-term climatic data were used because isolation data were pooled across several seasons.

\section{Results}

Species of Fusarium known to be pathogenic to small-grain cereals were isolated from crowns in 409 crops of wheat, barley or durum wheat out of 453 surveyed (Table 1). Among crops showing symptoms of stem browning from which Fusarium species were not detected, Bipolaris sorokiniana was commonly isolated in New South 
Table 2. Number of crops with more than 15 isolates of Fusarium species from 25 plants, isolates of $F$. culmorum as a percentage of total Fusarium, and selected climate parameters for districts around meteorological stations in Victoria and South Australia

\begin{tabular}{|c|c|c|c|c|c|}
\hline Meteorological station & No. crops & $\begin{array}{c}\text { Fusarium culmorum } \\
(\%)\end{array}$ & $\begin{array}{l}\text { November } \\
\text { rainfall } \\
(\mathrm{mm})\end{array}$ & $\begin{array}{l}\text { Annual rainfall } \\
(\mathrm{mm})\end{array}$ & $\begin{array}{c}\text { January mean } \\
\text { temp. } \\
\left({ }^{\circ} \mathrm{C}\right)\end{array}$ \\
\hline Kimba SA & 2 & 0 & 23.4 & 349.0 & 23.3 \\
\hline Loxton SA & 2 & 0 & 21.6 & 273.5 & 23.0 \\
\hline Maitland SA & 3 & 0 & 28.0 & 504.4 & 22.0 \\
\hline Minnipa SA & 2 & 0 & 20.0 & 325.6 & 23.3 \\
\hline Ouyen Vic & 7 & 0 & 26.4 & 333.9 & 23.7 \\
\hline Pallamana SA & 2 & 0 & 26.8 & 344.6 & 21.0 \\
\hline Beulah Vic & 9 & 0.5 & 28.4 & 377.0 & 22.3 \\
\hline Kadina SA & 14 & 0.7 & 22.2 & 390.1 & 23.2 \\
\hline Birchip Vic & 8 & 1.7 & 26.5 & 374.1 & 22.4 \\
\hline Cleve SA & 6 & 1.7 & 27.4 & 405.4 & 21.7 \\
\hline Roseworthy SA & 10 & 2.5 & 27.7 & 440.3 & 22.4 \\
\hline Maryborough Vic & 2 & 2.6 & 38.4 & 531.4 & 20.7 \\
\hline Snowtown SA & 5 & 11.5 & 24.8 & 406.3 & 22.9 \\
\hline Warracknabeal Vic & 7 & 11.6 & 29.7 & 410.4 & 22.1 \\
\hline Nhill Vic & 5 & 12.3 & 29.5 & 416.1 & 21.2 \\
\hline St Arnaud Vic & 4 & 13.4 & 34.7 & 510.2 & 21.5 \\
\hline Swan Hill Vic & 5 & 17.3 & 25.8 & 348.5 & 23.4 \\
\hline Jeparit Vic & 3 & 25.4 & 28.0 & 385.0 & 22.1 \\
\hline Georgetown SA & 6 & 25.9 & 30.7 & 473.8 & 23.1 \\
\hline Charlton Vic & 5 & 26.9 & 28.4 & 430.8 & 22.1 \\
\hline Horsham Vic & 12 & 31.0 & 33.7 & 450.3 & 21.5 \\
\hline Kybobolite SA & 5 & 42.4 & 37.3 & 554.3 & 19.8 \\
\hline Bordertown SA & 5 & 82.8 & 66.0 & 541.0 & 21.7 \\
\hline Warrambine Vic & 17 & 83.0 & 62.9 & 724.2 & 19.0 \\
\hline Hamilton Vic & 8 & 88.5 & 51.5 & 688.5 & 18.6 \\
\hline Lismore Vic & 8 & 90.4 & 55.8 & 624.7 & 19.1 \\
\hline Correlation with $\%$ F culmorum $\left(r^{2}\right)$ & & & 0.835 & 0.676 & 0.54 \\
\hline
\end{tabular}

Wales and Queensland, whereas symptoms of take-all or nodal browning due to foliar pathogens were common in the southern states. Some crops sampled after harvest yielded high levels of mycoparasites, especially Pythium oligandrum, Clonostachys rosea (syn. Gliocladium roseum) and Melanospora s. lat. species, which interfered with identifications. Results are, therefore, reported only for cultures that could be positively identified to species.

F. pseudograminearum was the most common species isolated in all regions except the Victorian high-rainfall region and South-East South Australia. F. culmorum was the only other species isolated frequently. Less than ten isolates of each of $F$. graminearum, $F$. crookwellense and F. avenaceum were found, suggesting that they were insignificant as causes of crown rot in Australia. F. acuminatum was common in some samples, but isolates of this species did not cause crown rot in pathogenicity tests (J. I. Dennis, unpublished) so it has not been considered further.

In Queensland and New South Wales, F. pseudograminearum was almost the only pathogenic species isolated (Table 1). F. culmorum was isolated from only three plants in Queensland, from Formartin and Gray's Gate on the Darling Downs. F. culmorum was not isolated from any samples collected in New South Wales.

F. culmorum was the predominant species isolated in the Victorian high-rainfall region and the adjacent South-East region in South Australia (Table 1; Fig. 2). More than 70\% of isolates from these regions were of F. culmorum, and this was the dominant or only species found in the majority of crops in these regions. F. culmorum was also isolated at moderate frequencies from the medium-rainfall and low-rainfall regions of Victoria (Table 1), although F. pseudograminearum was the dominant species in most crops in the latter regions (Fig. 2).

F. pseudograminearum was the most common species isolated in the Mid-North region of South Australia, although $F$. culmorum was found in 7 of 51 crops and accounted for $7 \%$ of total isolates (Table 1). F. culmorum was isolated only infrequently in the Murray Mallee, Yorke Peninsula and Eyre Peninsula regions of South Australia.

When correlations were calculated between the proportion of isolates of F. culmorum in districts in Victoria and South Australia (Table 2) and climate variables, the 


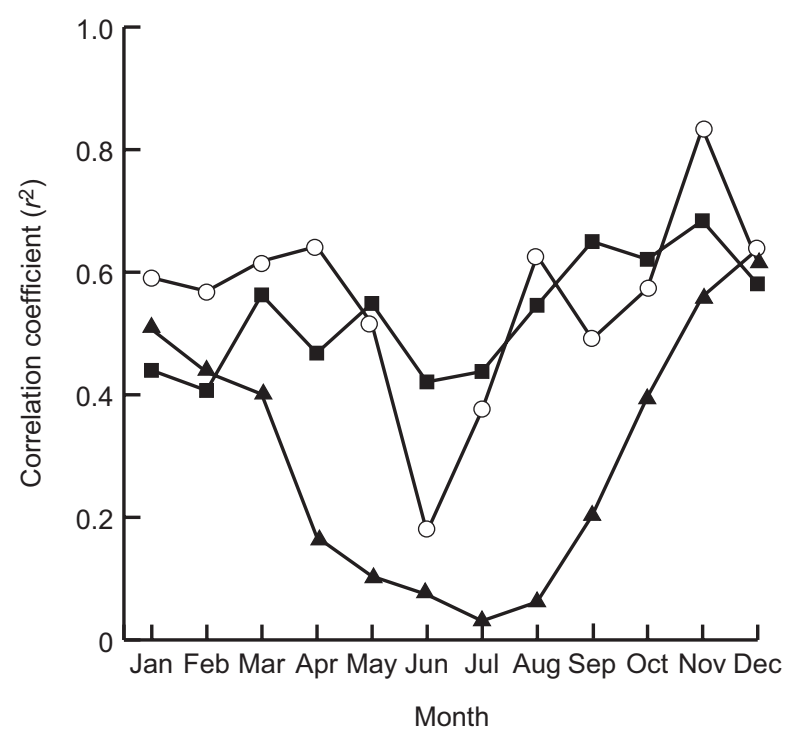

Fig. 3. Correlations $\left(r^{2}\right)$ between proportion of Fusarium culmorum among isolates from districts around meteorological stations in Victoria and South Australia, and long-term average monthly maximum $(\boldsymbol{\square})$ and minimum $(\boldsymbol{\Delta})$ temperatures and rainfall $(\bigcirc)$.

strongest correlations were with monthly rainfall and temperature parameters at the end of the season (November and December) and over summer (Fig. 3). The strongest correlation, $r^{2}=0.835$, was found with November rainfall. The regression equation was

$$
\text { F. culmorum }(\%)=-51.8+2.26(\text { November rainfall })
$$

and the regression was highly significant $(P<0.001)$. This predicts that $F$. culmorum would be the dominant species in districts in these states where average November rainfall is greater than $45 \mathrm{~mm}$.

The strongest correlation with the temperature parameters tested was a negative correlation with mean temperature in November $\left(r^{2}=0.704\right)$. Negative correlations with mean temperature in January $\left(r^{2}=0.54\right)$, maximum temperature in January $\left(r^{2}=0.44\right)$ and with growing degree days during the wheat season $\left(r^{2}=0.523\right)$ were weaker, although still significant. Annual rainfall had a significant positive correlation $\left(r^{2}=0.676\right)$ with proportion of F. culmorum isolations (Table 2).

\section{Discussion}

This survey confirmed the dominance of F. pseudograminearum among Fusarium species associated with crown rot in most of the eastern Australian grain belt (Burgess et al. 1975). However, it also found that F. culmorum was common and widespread in cooler, wetter areas of Victoria and South Australia.

As expected, F. pseudograminearum was almost the only pathogenic Fusarium species isolated from crops affected by crown rot in northern New South Wales and Queensland, traditionally the areas most greatly affected by the disease (Murray and Brown 1987). Authenticated cultures of F. culmorum had been isolated from several locations on the Darling Downs in the 1970s and 1980s (Backhouse and Burgess 2002). However, in this survey only three isolates were found among 30 crops from the Inner Downs, the area from which most previous records had come. F. pseudograminearum can, therefore, now be considered the only crown rot pathogen of significance in the northern grains region.

Southern New South Wales was not specifically targeted in this survey, and data were obtained from only a few crops. Only $F$. pseudograminearum was isolated from these. It is possible that F. culmorum may occur in southern New South Wales, but it is unlikely to be important. Climate matching using BIOCLIM suggested that most of New South Wales was outside the predicted distribution of $F$. culmorum (Backhouse and Burgess 2002) and earlier surveys in the south of this state showed that $F$. pseudograminearum was the predominant pathogen (Burgess et al. 1975).

The outstanding feature of the survey was the relative importance of F. culmorum in Victoria and South Australia. The dominance of $F$. culmorum in the high-rainfall $(>500 \mathrm{~mm})$ areas is significant because cereal production is increasing in these areas and crown rot caused by this species is starting to become a problem (G. J. Hollaway, unpublished). F. culmorum was known to be widely distributed in these states (Backhouse and Burgess 2002) but it was assumed to be unimportant in the main cereal-growing areas (Chambers 1972; Burgess et al. 1975). The survey confirmed the claims that $F$. culmorum was common in the Wimmera and Southern districts of Victoria (Geach 1932; Chambers 1972), but leaves open the possibility that the extrapolation of this to other areas of Australia (Butler 1961) was a result of poor identification (Chambers 1972). Presumably, Burgess et al. (1975) and Wearing and Burgess (1977) failed to detect F. culmorum in Victoria because most of their sampling sites were in lower-rainfall areas in the Mallee or northern Wimmera where F. pseudograminearum predominates.

Climatic analysis of historical distribution records suggested that in southern Australia F. culmorum was restricted to areas with mean temperatures in the warmest quarter less than $22^{\circ} \mathrm{C}$ and mean annual rainfall greater than $350 \mathrm{~mm}$ (Backhouse and Burgess 2002). However, that analysis could not determine the prevalence of $F$. culmorum relative to $F$. pseudograminearum within this favourable area. In the present study, intensive sampling enabled estimation of the relative frequencies of the two species and correlation with more detailed climate parameters than are available in BIOCLIM (Backhouse and Burgess 2002). The monthly pattern of correlations with rainfall and temperature suggested that the strongest influence of climate on relative 
frequencies of the two species occurred at the end of the season, in November and December, and that rainfall may have a larger influence than temperature. The high correlations between rainfall and temperature in this region mean that it is not possible to separate the effects of each factor. However, the results of this correlation analysis suggest that it would be worthwhile looking for causal relationships between late-season environmental conditions and the relative prevalence of $F$. pseudograminearum and F. culmorum. These could include effects on competition for infection and colonisation of cereal stem bases and residues, relative mortality of the two species in residues, or agronomic practices related to climate that could affect the fungi differentially.

Smiley and Patterson (1996) also looked for correlations between climatic factors and the relative proportions of F. pseudograminearum and F. culmorum in the Pacific Northwest, USA. They found weak relationships with mean monthly temperature during July (equivalent to January in the present study), elevation (which they linked to January and July temperatures and growing degree days) and annual rainfall. In southern Australia, January temperatures, growing degree days and annual rainfall were not the best predictors of relative frequency of these two species. There is scope for re-analysis of the data of Smiley and Patterson (1996) to determine correlations with other factors, especially late-season rainfall.

The significance for disease management of the predominance of $F$. culmorum in southeastern South Australia and southern Victoria remains uncertain. For foot rot of rye and head blight of winter wheat and rye, there are strong correlations between resistance to F. culmorum and F. graminearum, suggesting that resistance to Fusarium is not pathogen-species specific (Miedaner 1997). However, this needs to be tested for $F$. pseudograminearum and F. culmorum on the most important susceptible cereals in Australia.

There are differences in epidemiology between species that may impinge on management. F. pseudograminearum survives the summers as mycelium in plant residue, and spores are considered unimportant as an inoculum source (Wearing and Burgess 1977). On the other hand, F. culmorum can also survive as soilborne chlamydospores (Sitton and Cook 1981). Spores of F. culmorum can be dispersed by rainsplash (Jenkinson and Parry 1994) and nodal infection by airborne inoculum of this species is common in some environments (Parry et al. 1994). It is not known whether F. pseudograminearum can behave in the same way in similar environments. Observations during this survey in Victoria suggested that the incidence of infection with F. culmorum was affected less by cropping sequence than was infection by F. pseudograminearum, which was higher after pastures or cereals than after broadleaf crops (G. J. Hollaway and G. Exell, unpublished). There is a need for comparative epidemiological studies of these two pathogens to determine whether different management strategies are required.

\section{Acknowledgements}

This work was funded by the Grains Research and Development Corporation. We thank Graham Exell and Boyd MacNamara for assistance with collection of samples.

\section{References}

Aoki T, O'Donnell K (1999) Morphological and molecular characterization of Fusarium pseudograminearum sp. nov., formerly recognized as the Group 1 population of $F$. graminearum. Mycologia 91, 597-609.

Backhouse D, Burgess LW (2002) Climatic analysis of the distribution of Fusarium graminearum, F. pseudograminearum and F. culmorum on cereals in Australia. Australasian Plant Pathology 31, 321-327. doi:10.1071/AP02026

Burgess LW, Summerell BA, Bullock S, Gott KP, Backhouse D (1994) 'Laboratory manual for Fusarium research (3rd edn).' (Department of Crop Sciences, University of Sydney: Sydney)

Burgess LW, Wearing AH, Toussoun TA (1975) Survey of fusaria associated with crown rot of wheat in eastern Australia. Australian Journal of Agricultural Research 26, 791-799.

Butler FC (1961) 'Foot and root rot diseases of wheat.' Department of Agriculture New South Wales, Science Bulletin No. 77, Wagga Wagga.

Chambers SC (1972) Fusarium species associated with wheat in Victoria. Australian Journal of Experimental Agriculture and Animal Husbandry 12, 433-436.

Fedel-Moen R, Harris JR (1987) Stratified distribution of Fusarium and Bipolaris on wheat and barley with dryland root rot in South Australia. Plant Pathology 36, 447-454.

Geach WL (1932) Foot and root rots of wheat in Australia. Fusarium culmorum (W.G.Sm.) Sacc. as a causal organism. Journal of the Council for Scientific and Industrial Research 5, 123-128.

Jenkinson P, Parry DW (1994) Splash dispersal of conidia of Fusarium culmorum and Fusarium avenaceum. Mycological Research 98, 506-510.

Klein TA, Burgess LW, Ellison FW (1990) Survey of the incidence of whiteheads in wheat crops grown in northern New South Wales, 1976-1981. Australian Journal of Experimental Agriculture 30, 621-627.

Magee CJ (1957) News from New South Wales. Commonwealth Phytopathological News 3, 26.

Miedaner T (1997) Breeding wheat and rye for resistance to Fusarium diseases. Plant Breeding 116, 201-220.

Millikan CR (1942) Studies on soil conditions in relation to root-rot of cereals. Proceedings of the Royal Society of Victoria 45 (NS), 145-195.

Murray GM, Brown JF (1987) The incidence and relative importance of wheat diseases in Australia. Australasian Plant Pathology 16, 34-37.

Parry DW, Pettitt TR, Jenkinson P, Lees AK (1994) The cereal Fusarium complex. In 'Ecology of plant pathogens'. (Eds JP Blakeman, B Williamson) pp. 301-320. (CAB International: Wallingford, UK) 
Price RD (1970) 'Stunted patches and deadheads in Victorian cereal crops.' Department of Agriculture, Victoria, Technical Publication No. 23, Burnley.

Sitton JW, Cook RJ (1981) Comparative morphology and survival of chlamydospores of Fusarium roseum 'Culmorum' and 'Graminearum'. Phytopathology 71, 85-90.

Smiley RW, Patterson L-M (1996) Pathogenic fungi associated with Fusarium foot rot of winter wheat in the semiarid Pacific Northwest. Plant Disease 80, 944-949.
Wearing AH, Burgess LW (1977) Distribution of Fusarium roseum 'Graminearum' Group 1 and its mode of survival in eastern Australian wheat belt soils. Transactions of the British Mycological Society 69, 429-442.

Received 31 March 2003, accepted 30 November 2003 